\title{
ILCEA
}

Revue de l'Institut des langues et cultures

d'Europe, Amérique, Afrique, Asie et Australie

14 | 2011

Traduction et Ergonomie

\section{Job Perceptions, Identity-Building and} Interpersonal Relations among Translators as a Professional Group in Northern Portugal

Perceptions du métier, identité professionnelle et relations interpersonnelles:

une étude sur les traducteurs du Nord du Portugal

\section{Fernando Ferreira-Alves}

\section{(2) OpenEdition}

\section{Journals}

Electronic version

URL: http://journals.openedition.org/ilcea/1119

DOI: 10.4000/ilcea. 1119

ISSN: 2101-0609

\section{Publisher}

UGA Éditions/Université Grenoble Alpes

Printed version

ISBN: 978-2-84310-203-5

ISSN: $1639-6073$

\section{Electronic reference}

Fernando Ferreira-Alves, « Job Perceptions, Identity-Building and Interpersonal Relations among

Translators as a Professional Group in Northern Portugal », ILCEA [Online], 14 | 2011, Online since 30 June 2011, connection on 20 April 2019. URL : http://journals.openedition.org/ilcea/1119; DOI : 10.4000/ilcea. 1119

This text was automatically generated on 20 April 2019

(C) ILCEA 


\title{
Job Perceptions, Identity-Building and Interpersonal Relations among Translators as a Professional Group in Northern Portugal
}

\author{
Perceptions du métier, identité professionnelle et relations interpersonnelles: \\ une étude sur les traducteurs du Nord du Portugal
}

Fernando Ferreira-Alves

1 Recent developments in the language industry scenario following globalisation trends have transformed translation practice into a strategic social, multidisciplinary phenomenon. Changes in the language service provision landscape have also led to the redefinition of the role and position of the translator as an autonomous, professionallyoriented subject and/or object of study within the social and human sciences. In order to understand translation as an industrialised, business-oriented category, it is also necessary to focus our attention on the actors involved-individuals and institutionsthat are part and parcel of the process of language service provision, by carefully mapping the links, relationships and hierarchies that are established in the field, according to different vectors.

2 Our perspective starts from the assumption that there are several constraints and requirements affecting translation practice in general based on new business-oriented patterns that need to be assessed accordingly. On the one hand, this configuration may account for its devaluation in terms of socio-professional status, while, on the other, it may explain why the role and place of the translator is actually being transformed into a new hybrid entity whose exact position is worth studying within such a diversified array of social and professional settings where translation practice actually occurs. 


\section{Translation, profession and professional culture: From market to individuals}

3 This research began by focusing attention on the so-called "professional collective identity" developed by translators in the course of their activity, as defined by Anthony Pym in the article "Training Translators and European Unification: A Model of the Market" (April 2000). The model applied is based on the notion that there is "a structurally fragmented market", marked by strong power relations, which is in some ways the logical consequence of globalisation and the result of the division that has been established in the heart of professional, intellectual labour. Based on the socioprofessional dynamics of a profession that is beginning to be seen through the "sociological eye", translation as an interdisciplinary social phenomenon is an increasingly interesting area of study in social sciences as it involves different agents who continuously internalize strutures, act in accordance with social values and social systems (Wolf, 2007, pp.4-31), are involved in social constraints and dynamics and operate in the same conceptual "actor-network scenario" (Latour, 1987, pp. 103-44).

4 How do we capture this notion of professional culture and professional dynamics as applied to translation practice? How do we frame this social field where professionalisation is constantly shaped and reshaped, where tensions and clashes occur, and where autonomy and control over the process and organization of labour are negotiated, whether symbolical or ideological, political or organizational. The truth is, as stated by Ester Monzó i Nebot, that there is a deficient level of socialization among the professionals and a resulting lack of common identity which obliges translators to simultaneously adapt themselves to and resist a highly competitive market. Lack of prestige, subservience, self-effacement, over-criticism, exposure, intra and interprofissional conflicts and organizational shifts, as well as the social values usually ascribed to the work of translators internally and externally (Monzó i Nebot, 2006, p. 173) are concepts that affect the life of translators and often put them in a fragile position as a profession, not only among theirs peers, but also among other converging, languagerelated professions which dispute the same professional field (see, for example, the cases of localization and audiovisual translation).

5 To help clarify certain terminological issues, the following operational definition of translation as a profession was used, borrowing concepts from the available literature on this subject (namely Wolf and Fukari, 2007, pp. 1-36; Monzó i Nebot, 2006, p. 155-76). Translation can be seen as a social-based, norm-driven activity, set within the scope of the "technical-intellectual labour", developed in a complex network system, within a specific community of practice (Wenger, 1999, pp. 43-9) where action and knowledge are shared, and where several actors or agents (people and institutions)-either social constructed mediating agents or socialised individuals (Meylaerts, 2008, pp.91-102)involved in the production of "immaterial and incorporeal goods" (Heilbron and Sapiro, 2007, p. 99) converge and interact, holding the commercial application of a specific area of organized knowledge that is institutionally validated and accepted. 


\section{The Portuguese translation market}

6 Despite the number of Portuguese speakers around the globe, Portugal remains a peripheral country where translation practice occurs mostly from English and other languages into Portuguese. As pointed out by Heilbron and Sapiro (2007), Portugal is a country that receives translations, where translation basically occurs from languages playing a central or hypercentral position, like English, from the core to the periphery (Heilbron, 2010), and where texts and other translated materials circulate from other languages. Visible or not, the fact is that translation pervades everyday life, be it in the form of a press release from a news agency, a menu from a restaurant, a financial report, certification of legal documents, or some useful piece of information/advice in an airport. The translation market has increased significantly in the last decade, mostly due to the number of books that have and are still literally "flooding" the desks of editorial staff in most publishing houses. Most of the literature that circulates in Portugal has been translated, a percentage that can easily reach $35 \%$, or even $45 \%$ in terms of the national output, according to Heilbron and Sapiro (2007).

7 However, it would be misleading to overstress the importance of literary translation in the Portuguese scenario, especially considering the political, economic and social weight of technical documentation and scientific texts that usually gravitate around the socalled concept of translated products. If one looks at the booshelves of an ordinary supermarket or bookshop, one is confronted with a massive circulation of translated texts, a few of which are literary but most of which relate to scientific and technical domains. According to the data gathered in this research, literature is only the tip of the iceberg of normal, average translation practice in Portugal. It is the most visible as well, especially because of the status and implications of cultural products in society-mostly of literary origin-and the strong commercial policies adopted by the major publishing houses. However, hidden underneath the literary "crust" there is an immense territory formed by technical, specialised material whose economic capital is by far more valuable than the rest. The usual split between technical and literary translation is therefore quite visible in social terms in Portugal, a finding that tends to be in tune with Heilbron and Sapiro's conclusion that "literary and academic translators are thus distinct in many ways, including economically, from the whole set of "technical" and professional translators" (Heilbron and Sapiro, 2007, p. 102).

Still, as an empirical conclusion it is possible to say that people are translating more than ever. According to four of the most important translation agencies operating in Portugal, the volume of translated materials has practically doubled. Because of globalization policies worldwide there has been a considerable increase in translation output in terms of translated materials, something that has imposed new constraints on the profession in terms of speed, quality and accuracy. Following this commoditisation of translation services, there are more people literally consuming translated materials than ever, thanks to an increase in the sales of consumer goods, appliances, tools, technology, electronics devices, gadgets, games etc. This diversification is also reflected in a higher degree of thematic specialisation, text diversity and language combinations/pairs. As a result, translators are increasingly faced with higher and fiercer competition, more specialisation, new standards and patterns in terms of demand, accuracy and quality, and, 
of course, new power relations and higher levels of exposure and social criticism resulting from the leading role that is ascribed to the profession from outsiders.

The impact of this conjuncture is reflected in the proliferation of translation services at a national basis, both professional and non-professional, thus leading to the creation of a grey area, a sort of no-man's land, where translation practice normally occurs with little certification, institutional recognition or validation. Despite the growing number of translators operating in Portugal, their situation is precarious since most of them are still amateurs or semi-professionals and can hardly be considered professionals at all, in the sense of someone "engaged in a profession, especially one requiring advanced knowledge or traning" or someone "engaged in a specific occupation or activity for money or as a means of earning a living, rather than as a pastime" (Oxford Short English Dictionary, 1993).

The market is still fragmented and non-regulated and, from the institutional perspective of government recognition and certification, the profession is largely invisible, underestimated and non-recognised, relegated to a minor category. For example, the Index of Economic Activities (CAEs), according to which a professional is registered in the Finance Department for tax/fiscal purposes, classifies translators under categories of activities associated with secretarial jobs, language teaching, tutorials and post-office related professions (74830/74850), together with "other services rendered to companies", such as photocopying (74842 / 74872), stationery, bookshops, news agents, etc. So much for social recognition. When applied to our reality, Anthony Pym's statement about the translation market in Europe, according to which "the growth of the sector has been so fast, the power structures so dynamic and fragmentary, [...], that there are relatively few official regulations in force and no question of unionism or collective action" (Pym, 2000), seems quite up-to-date.

11 The way professionals and agencies promote their services is quite diversified as well, which means that people tend to look for identical singularities in the so-called associated professions within the language industry, thus showing how uncertain, diffuse and dispersive the professional field associated with this activity is. The focus on peripheral professions and other related services is clearly demonstrated by the way people tend to associate translation services with language learning, namely language schools, temporary work, part-time jobs, secretarial jobs, photocopying services, electronics or services connected with the organisation of social events. There are also constant links to management and marketing activities, accounting and legal jobs. An analysis of the Porto phone directory, the second most important city of Portugal, with regard to the evolution of translation services reveals that from 1996/1997 onwards there has been a $50 \%$ increase in the number of people offering translation and other languagerelated services. Although translation is classified under the heading "Translators and Interpreters" (p. 1003), and despite being a normal commercial procedure in the sense that these events often require translation services, the truth is that there are also associated links to "Organization of Congresses and Parties - Social Events, Receptions and Services - Tourist Guides".

12 It seems as if language, especially translation, is always a service that can be announced everywhere, and assumed as a self-evident truth to most people. Another trend that characterises advertising strategies is that translators tend to organise themselves around the concept of "ghost agencies", which are basically single-person or one-person companies, in the sense of an entrepreneur as an individual who chooses to go into business by himself, whether as free agent, freelancer, self-employed or home based 
business owner. This seems to corroborate the conclusions drawn by Galvão (2006) and Ferreira-Alves (2005) that most of these agencies are SMEs or micro-enterprises, as defined by the OECD (2006), or even single-person companies that operate mainly as intermediaries for the so-called SLV (Single-Language Vendors) and MLV (MultiLanguage Vendors) working at an international level, and are used to applying oldfashioned, unprofessional management routines marked by improvisation and lack of a coherent strategic planning. This leads to the creation of vicious circles that are hard to fight and break, because the image projected by translation service providers is precisely what seems to prevent the market from developing and growing.

Some indication of the market's distinctive features, how it operates and how social and commercial dynamics are established among translators as a professional group, may be obtained by studying one of the most famous online vortals/portals, where translation services are announced and bought worldwide. The internationally acclaimed ProZ, as it is usually known, is described and announced in its website as "the translation workplace", designed for freelance translators/interpreters, translation companies, translation students. The project is divided in two major areas. ProZ.com (the community) is a group of language professionals that includes translators, interpreters, translation companies, and their clients. Proz.com (the site) is a marketplace and workplace, where thousands of language professionals exchange job and term information every day. Serving the world's largest community of translators, Proz.com delivers a comprehensive network of essential services, resources and experiences that enhance the lives of its members ${ }^{1}$.

According to information found on the company's website, the Proz.com mission is to provide tools and opportunities that translators, translation companies, and others in the language industry use to network, expand their businesses, improve their work, and experience added enjoyment in their professional tasks. This useful resource for translators is a professional online forum, where translators actually announce and sell their services to a vast community of users and potential clients. It is one of the most important online tools for language service providers and also one of the most soughtafter locations for clients and end-users. Apart from its commercial use, the site is based on a strong sense of community where information is shared among professionals and data exchanged between peers and partners alike. It is also a very important search/ research tool for its terminology databases, information/knowledge retrieval data and language/domain field directories associated with language pairs and domain fields or areas of specialisation.

Translation into and from Portuguese is of course one of the major language combinations/pairs offered as a service in the online directory. For example, from July to November 2007, the ProZ directory showed a total number of 7,656 "Translation Service Providers" from English into Portuguese registered in its directory, of which almost 20\% were from Portugal ${ }^{2}$. Visualisation of the professionals profile is formatted according to standardised information that quite often leads to the construction of a specific professional identity and social image, both endogenous and exogenous/intrinsic and extrinsic, thus showing the different aspects of a strongly diversified and heterogeneous profession, marked by fragile relational networks, different levels of socialization among professionals, dichotomical characteristics, hybrid status and discourse, divergent organizational approaches and a lack of coherent, distinctive structures able to sustain 
the profession as an autonomous established field in society as a whole with a common socioprofessional identity.

A study of how professional translators present themselves to work providers, reveals oscillation between a high-professional tone and a weak, almost amateur-like discourse, a phenomenon which underlines the ubiquitous tension between the different professional approaches, between specialist vs generalist, dispersion vs fixation, experience vs novice, autonomy $v s$ subordination, weakness and vulnerability $v s$ self-assurance, inner $v s$ outer features, and ultimately visibility $v$ invisibility, all factors often associated with the way such people actually construct their professional identity and represent themselves as social actors, playing a social role that is validated and ratified by society and clients, according to power structures and prescriptive, norm-based behaviours.

\section{Methodology and preliminary hypotheses: Why an ethnographic approach based on personal narratives?}

17 A former research project initiated in 2005 called "The profile of translation companies in Portugal - A brief sociological survey"3 helped identify the major underlying dynamics behind the translation industry at a national level, by characterising the sector as well as the conditions in which some of the most important translation agencies usually operate in Portugal, with obvious implications regarding individual translators as well.

This research helped map the translation market scenario and led to the current research topic, i.e. the study of a particular controlled group in a specific geographical context, by focusing attention not only on the group dynamics of professionalization, but also on the individuals' perceptions about their activity. Based on an interdisciplinary approach, I found it useful to borrow some of the tools used in social research to look at translation from a sociological/ethnographic perspective by changing the focus from text as a "symbolical cultural product" to context-driven, system-organised dynamics where individuals act and behave, constructing their own professional in relation with others and with themselves.

Therefore, some of my major research questions were clearly focused on intangible issues that are hardly visible in a quantitative approach, such as the definition of professionalism and professional culture with regard to such a dynamic dispersive group of individuals: How do we capture professional perceptions among translators as a group? How do we define professionalism and what does it mean for translators? How do translators see themselves in society? What set of concrete parameters is used to characterise a "professional translator"? How do translators construct their own professional identity in society?

20 Translators are individuals who are able to reflect upon their position among their own professional group and in society as well. They may be quite uncertain about their role in society, they may have some misconceptions and prejudices about their place and importance in a social system, but they have clear ideas of how society looks at them from the outside. They are aware of their deficit in terms of status, but conscious of their place in-between, in a sort of clichéd no-man's land where internalized norms interact and affect their practice, leading them to a peripheral place in the same social system they operate in, and where "professional norms" and "expectancy norms" often clash (Chesterman, 1993). Only a qualitative-oriented approach based on intensive observation 
and field work, speaking with them and sharing their points of view, discussing issues and observing how they share their perceptions about their identity as professionals and social agents, will make it possible to outline the shape of their path towards professionalisation.

One of the reasons for choosing this object of study has to do with the fact that, as a professional translator and translator trainer, I am confronted with the need to define, in Bourdieusean terms, the so-called professional fields within a specific habitus, characterised by distinctive traces in terms of everyday practice. The need to detect "the contours of translation as a recognized, social category" (Hermans, 1997, p. 42) and isolate translation as social-oriented, norm-governed phenomena where several agents interact in different action/context-driven dynamics is, therefore, crucial to help situate translation as a legitimate object of study in itself, and establish the exact nature and territory of its professionalism.

Therefore, the goal of this study is to share an empirical testimony marked by a personal and professional reflection on the process of constructing a professional identity associated with a new profession that is strongly subject to external constraints, within a geographically-circumscribed context knowing for sure that one of the crucial issues a new profession is faced with it is its social pertinence, real or symbolic, innate or constructed.

23 I quite agree with Peter Flynn's proposal according to which "we can approach translators as people who also use language in particular ways in relation to particular activities and also as people holding and expressing opinions and values about the nature of the activity they are involved in" (Flynn, 2005). The study of the narratives produced by professional translators about themselves and about their professional reality, together with the analysis of their tacit, implicit knowledge will ultimately help us draw the limits and boundaries of a professional identity that is vague and diffuse, conflictual and unconsolidated in social terms. In fact, we are, indeed, dealing with professionals who have common internal consolidated "repertoires", are in the process of consolidating their knowledge, have different levels of self-esteem, and do seek some sort of legitimacy, whether symbolical or institutionalised, that will empower them to go on the market and use their professional skills accordingly. Therefore, my methodological approach will privilege sharing routines, expectations, anxieties, frustrations and the daily, average application of a specific professional, norm-based behaviour, by fostering the recognition of a specific professional knowledge on the field. This self-reflexive framework will help us study some discursive markers, namely via the application of several variables used by van Leeuwen in discourse analysis regarding representation of roles by social actors, according to which specific categories and values can be attached to the discourse produced by agents in a certain time and place (van Leeuwen, 1998, pp. 169222).

24 Another important methodological contribution was the one adopted by Shlesinger and Sela-Sheffy in their article "Strategies of image-making and status advancement of translators and interpreters as a marginal occupational group" (2008), which helped draw a prototypical profile of the type of professionals operating in the market. Indeed, and as stated by Shlesinger and Sela-Sheffy "this classification, however rough and inadequate, suggests some crucial differences in the role definition; languages translated; conditions, volume and prices of work; qualifications; training; recruitment and career patterns; 
organizational frameworks; and other parameters that distinguish between the different jobs, and also translate into occupational hierarchies" (Shlesinger and Sela-Sheffy, 2008).

In order to contextualise this research, I adopted a quantitative approach according to which a survey called "The Professionalisation of Translation in the North of Portugal" was developed and published online and launched from 7 January 2008 to 30 March 2008. The survey was aimed at studying some of the important issues associated with the notion of professionalisation and typifying the major background against which professional dynamics occur among all the agents involved in the process. The survey was divided into 20 items ranging from identification, skills, expert knowledge and academic background to working conditions, status, social recognition and professional perceptions, including prices and services, as well as ethical issues and customer/market relations.

\section{Who are they? Conclusions and results}

Who are these translators after all? What do they do? When and where did they start working? How do they interact with other agents? What do they feel about their job?

Before implementing the survey, a data base of translators from the North of Portugal was built, with a total of approximately 900 participants. The number of potential respondents was based on personal contacts, phone directories, the Internet, Google, different fora such as ProZ, Translator's Cafe, etc, contacts from translation agencies and professional associations, such as the APT (Portuguese Translator's Association), among others.

Regarding responses to the survey, by the time it was closed 437 respondents had started the survey, among which 244 managed to complete the 88 questions that comprised the whole survey, thus accounting for a total of $55.8 \%$ of the translators involved.

As to the identification profile of the respondents, namely place of origin, place of work or district, $53.8 \%$ (232 people) come from the district of Porto, which is the second biggest and most important city of Portugal. 24.8\% (107) come from Braga, whereas $7.7 \%$ (33 respondents) are from the district of Aveiro, thus sugesting that translators follow the national demographic tendency to be closely based next to the major city centres and not in the periphery or in the countryside.

The demographic data collected points to predominantely female interviewees, with a broad and balanced age range. The great majority of the translators operating in the North is female with $77.3 \%$ (333), against $22.7 \%$ (98) male. Most of the participants are positioned within the age group of 21-30 years-old, representing $44.3 \%$ (191) of the sample. In second place, we find people between $31-40$ years old (34.6\% 191 respondents), whereas the third position is occupied by people between 41-50 years old, representing $13.2 \%$ (57 people). Globally speaking, and in terms of working experience, these are people that started translating 3-5 years ago (26.9\%), and also 610 years ago (22.6\%), which unfortunately indicates that most of them are quite young and computer-literate but do not seem to have much experience of the market. Also, for most of them, $45.2 \%$, translation is considered to be the main activity, whereas $29.3 \%$ say it is a secondary activity, and $25.4 \%$ describe it is a part-time/temporary or occasional activity. 
31 Regarding qualifications and academic profile or background, 57.7\%, i.e. 232 respondents, have some type of degree or higher education, whereas $15.4 \%$, i.e. 62 translators, mentioned having a master's degree. When asked if they had specific training in translation, the great majority said they had some training in translation, namely $69.3 \%$ (269), whereas $30.7 \%$ confessed having no such specialisation. As to the type of training in translation, most of the translators mentioned having a general-based type of training (55.2\% - 155 respondents), whereas $44.8 \%$, i.e. 126 people mentioned having some sort of training in namely specialised translation, in specific fields.

Some areas or fields of knowledge came out as the most frequent in terms of demand. This variable was studied by selecting those domains most requested by their clientele. The most sought-after area chosen by the great majority of respondents was legal translation, with 66 responses, in a total of 339 answers. In this category is included the translation of legal documents connected with law, as well as certifications, affidavits, translation of official documents, notary certifications, etc. The second position was occupied by a type of translation that was characterised by the respondents as purely technical, especially in the fields of automotive engineering involving subjects like mechanical engineering, car industry, mechanics, etc., (59 responses). The translation of informatics, localisation, software and computer science was chosen by 31 respondents as the third most important field of work, whereas literary translation was the fourth (26 respondents). The fifth position was occupied both by medicine and health sciences, as well as audiovisual translation.

Even though professional translation services cover a wide area, it is possible to conclude that the four most important areas according to market demands are undoubtedly legal translation and translation of official documentation, as well as technical translation, namely documentation and texts in the fields of mechanical engineering, automotive and civil engineering, followed by computer science, informatics and localisation.

The traditional distinction between literary $v s$ non-literary or technical translation was an important question for this research since it revealed some useful findings closely connected with the perceptions translators have about their job. When asked whether or not they would define their activity as literary or technical, the great majority of answers revealed that $86.1 \%$, i.e. 279 translators, considered they practiced in technical and specialised fields, whereas only $13.9 \%$ of the persons surveyed mentioned literary translation as their major occupation (45 responses). However, when asked to name the major fields in which they worked, many respondents mentioned literary translation, which may indicate that values such as status and prestige associated with literary translation are deeply internalised in their behaviour. It is also worth mentioning that for most of these people literary translation is an occasional activity, i.e. people have done just a few literary translations in the course of their lives and do not usually make a living from this type of activity, especially with the rates practiced by publishing houses and the high competition that prevents translators from translating regularly and maintaining a long, stable professional relationship with their employers. Most of the persons surveyed who mentioned literary translation, are precisely those that have another job, and to whom translation is a secondary activity or a part-time job.

It was also my intention to survey professional perceptions regarding translator practice, namely attitudes regarding professionalisation. When asked if they considered themselves to be professional translators, $75.6 \%$, i.e. 217 respondents, answered affirmativelly, whereas $24.4 \%$, i.e. 70 answered negatively. Later on, these professionals 
were asked to assess their performance as professional translators. $63.4 \%$, i.e. 182 translators, considered their practice to be evaluated as "Good", whereas $21.3 \%$ (61) mentioned "Excellent". However, when asked about professional recognition in Portugal, more than $50 \%$ of the respondents, (50.2\%) 144 admitted not being recognized or valued at all. Only $30.7 \%$ of the interviewees, i.e. 88 translators admitted having some kind of recognition, whereas the same negative impression was stressed by $17.8 \%$ of the respondents who answered that the profession was relatively recognised at a national level (51).

With reference to the degree of dissatisfaction with the current status of translation in Portugal, the answers showed a similar negative trend, especially because most of the respondents answered both "Unsatisfied" (55.7\% - 160) and "Completely unsatisfied" (17.8\% - 49 responses). A further question was aimed at questioning the overall degree of satisfaction with the translation market in Portugal. Once again, the answers revealed a negative trend, 54.7\% (157 translators) answered "Unsatisfied", whereas $24 \%$ said they felt "Satisfied" with the translation market (i.e. 69 responses).

The same negative trend appeared regarding the degree of satisfaction with the ethical levels of the profession. $41.8 \%$ were not satisfied (120 responses), and $33.8 \%$ (97) said they feelt satisfied with the ethical aspects of the profession.

Generally speaking, the comments made by translators about their profession seem to reveal a negative, uncertain and weak perception of what the profession looks like and how they position themselves in this field. For example, when asked if they considered Portuguese translators to have the adequate training to practice their job, most of them answered "No", i.e. 63.8\% (183 responses), and only a small percentage of $36.2 \%$ (104 respondents) answered "Yes".

However, this negative tendency seems to be inverted when translators are invited to talk about vocational aspects. The vast majority, 81.2\% (233), answered "Yes" to the question of whether or not the profession of translator corresponded to their vocation. This is something that is normal and seems to be quite frequent when dealing with personal perceptions. For example, the question "Being a translator is important to your selfesteem/self-image?" was posed to them, and the majority, i.e. about $68.3 \%$ (196), answered "Yes", whereas the rest, 31.7\% (91 responses), answered "No".

Working conditions were also assessed in this survey. Regarding the level of satisfaction with the general conditions according to which translators do their jobs, more than $50 \%$ $(55,1 \%)$ translators confessed they were not satisfied with their working conditions. Moreover, when confronted with perceptions like financial/economic safety and security in relation to their profession, most of the people surveyed said they did not feel safe at all with the profession. $71.2 \%$ (200 people) answered negativelly, and only $28.8 \%$ (81 people) answered "Yes". But, generally speaking, translators in the North of Portugal identify themselves with the professional group of translators to which they allegedly belong. $56.1 \%$ of them, i.e. 161 respondents, said they identified themselves with the professional group as a whole, whereas $43.9 \%$, i.e. 126 people answered "No". Regarding satisfaction with their quality of life, most translators felt satisfied and happy with it, namely $66.8 \%$ (187 people). However, they feel that the image of translators in society is, in general, not positive at all, meaning $63.8 \%$ of the total number of responses (183 people). Also, regarding this question, globally, they think that the general quality of translation in Portugal is medium or average, thus accounting for $54.7 \%$ of the total responses (157 respondents). 


\section{Conclusions}

41

\section{(1)}

ation activity actually takes place, one of the major findings concerns the considerable depth and reach of the market. The other important finding is connected with the very fragile position of translators regarding their field, not only subject to internal and external constraints and power structures, but also lacking references, as well as coherent, objective strategies according to which a specific professional trajectory could be adopted. A third important conclusion is linked with the construction of a professional image or identity. By observing and speaking with some of the translators surveyed we get the feeling that they are, indeed, talking about the reflection and projection of an image that occurs via their own discourse, i.e. the construction of a forged social and professional identity, of people staging and playing social roles and social games "in the social make-up of translation" (Wolf and Fukari, 2007, p. 11). Another crucial point has to do with the considerable number of negative impressions associated with professionalism, from an individual perspective and in relation with the translation profession as a whole, namely by reproducing conventional and over-critical clichés associated with the way outsiders usually see the profession, almost as if rejecting their own profession. Nevertheless, the intense effects of globalisation on the language industry pose new threats and present new challenges to all the agents engaged in the production and provision of multilingual services that will eventually lead to the reshaping of the concept of professionalism as applied to translation.

There's also the risk of fragmenting and diluting the individual in the mesh of web-based, network systems in which agencies and translators usually operate. The idea of being "lost in translation" does actually make sense in this professional field. This is something that should be dealt with in order to cope with the winds of change that are affecting the profession, in particular at a time when the vast majority of the most recent publications on the theme (Thomson-Wohlgemuth, 2004; Pym, 2005 and 2006) seem to be redirecting our attention to the essential role played by the human element that has seemed to have become lost in the translation process.

Another important issue worth studying is the effect of the so-called business-oriented dynamics in the translation process itself, and in professionalism, in particular. The attention given to the increasingly important role of business culture and businessoriented language, derived from marketing studies and management theories is, in fact, a frequent issue for these people, who sometimes seem to replicate business-oriented models of communication via the interiorisation of new norms, standards, formats, regulations and precepts which are specifically oriented towards marketing, managing and assessing the translation process.

45 Finally, one of the important issues left open concerns professional perceptions, identitybuilding and general strategies of status improvement used by translators. For example, despite the differences and constraints, all respondents tend to express frustration at their non-standardized working conditions and the fact that their professional authority is constantly being called into question, a pressing point in this research which is 
confirmed by schlesinger (2008). It also relates to different strategies of status improvement adopted by different groups of translators (Sela-Sheffy, 2006), namely professionalization in the realms of non-literary translation (technical translation, interpreting and subtitling, localization); emphasis on individual-centeredness, intellectual stature, technical skills and the need to find legitimatory devices in competing professional territories; the need to define and legitimise a real, effective professional field; a tendency towards an over-exaggerated almost delusive discourse borrowed from marketing and the construction of a symbolically-staged, self-defensive identity that does not necessarily correspond to reality. The perpetuation and/or subversion of Venuti's famous dictum about the translator's invisibility as an essential requirement of acceptability seems to be quite pertinent these days when dealing with professional issues as applied to identity-building, according to which translators do actually seem to construct a self-centered non-person; or just simply play the social game, somewhere between over-visibility and complete self-effacement, as if invisible to the ouside world and visible to their own group. This leads us to a three-fold perspective:

1. As a "community of practice", translators feel the need to define their professional field(s) within a specific "habitus", characterised by distinctive traces in terms of everyday practice. Trying to draw the exact shape of their professionalism (i.e. defining its territory), as a recognized, social category.

2. It is not only the professional field associated with the activity which is uncertain, diffuse and dispersive-professionalization is also continuously shaped and reshaped, leading to the weak/fragile position of the translator within his/her field and constant subjecting to internal and external constraints, tensions and clashes.

3. The activity is strongly marked by contradictions and the tentative construction of a professional image or identity, i.e. "people staging and playing social roles and social games in the social make-up of translation" (Wolf and Fukari, 2007), or constructing a self-centered non-person (Goffman, 1990), playing the social game, somewhere between over-visibility and complete self-effacement, as if the recurrent dictum "lost in translation" could somehow be applied when speaking about their professional field.

\section{BIBLIOGRAPHY}

FERREIRA-AlVES Fernando, "O reenquadramento da formação de tradutores em contexto de trabalho”, Proceedings VIII Seminário de Tradução Científica e Técnica da União Latina, Lisbon, 2005.

FLYNN Peter, Linguistic Ethnography of Literary Translation: Irish Poems and Dutch-speaking Translators, Doctoral Thesis, University of Gent, 2005, 371 p.

GALVÃo Elena, "Entre inovação e tradição: viagem ao mundo dos compradores de serviços de tradução na zona do Grande Porto", Proceedings 5as Jornadas de Tradução da ESTG, Leiria, 2006.

HEILBRON Johan, Structure and Dynamics of the World System of Translation, International Symposium “Translation and Cultural Mediation" (UNESCO, 22-23 February 2010), 2010, available at <http:// portal.unesco.org/culture/en/files/40619/12684038723Heilbron.pdf/Heilbron.pdf> [accessed 3 May 2011]. 
HEILBRON Johan and SAPIRO Gisèle, "Outline for a sociology of translation: Current issues and future prospects", in Michaela Wolf and Alexandra Fukari (eds), Constructing a Sociology of Translation, Amsterdam and Philadelphia, John Benjamins Publishing Company, 2007, pp. 93-107.

HERMANS Johan and LAMBERT José, "From translation markets to language management: the implications of translation services", Target, vol. 10, no. 1, 1998, pp. 113-32.

LAMBERT José, “The Cultural Component Reconsidered”, in Mary Snell-Hornby (ed.) Translation Studies - An Interdiscipline, Amsterdam and Philadelphia, Benjamins (Translation Library), 1994, pp. 17-26.

LATOUR Bruno, Science in Action. How to Follow Scientists and Engineers through Society, Cambridge Mass., Harvard University Press, 1987, 274 p.

MEYLAERTS Reine, "Translators and their norms: Towards a sociological construction of the individual", in Anthony Pym, Miriam Shlesinger, and Daniel Simeoni (eds), Beyond Descriptive Translation Studies: Investigations in homage to Gideon Toury, Amsterdam and Philadelphia, John Benjamins, 2008, pp. 91-102.

MONZó I NEBOT Esther, “¿Somos profesionales? Bases para una sociología de las profesiones aplicada a la traducción”, in Arturo Parada and Oscar Díaz Fouces (eds), Sociology of Translatio, Vigo, Universidade de Vigo, 2006, pp. 155-76.

PARADA Arturo and Díaz Fouces Oscar (eds), Sociology of Translation, Vigo, Servizio de Publicaciones do Universidade de Vigo, 2006, 231 p.

PYM Anthony, Training Translators and European Unification: A Model of the Market, 2000, available at <http://usuaris.tinet.cat/apym/on-line/training/Luxembourg.pdf> [accessed 17 June 2011].

SELA-SHEFFy Rakefet, "The Pursuit of Symbolic Capital by a Semi-Professional Group: The Case of Literary Translators in Israel”, in Michaela Wolf (ed.), Übersetzen - Translating - Traduire: Towards a "Social Turn"?, Münster, Hamburg, Berlin, Wien, London, LIT., 2006, pp. 243-62.

SELA-SHEFFY Rakefet and SHLESINGER Miriam, "Strategies of Image-Making and Status Advancement of Translators and Interpreters as a Marginal Occupational Group", in Anthony Pym, Miriam Shlesinger, and Daniel Simeoni (eds), Beyond Descriptive Translation Studies: Investigations in homage to Gideon Toury, Amsterdam and Philadelphia, John Benjamins, 2008, pp. 79-90.

STEYAERT Chris and JANSSENS Maddy, "Language and Translation in an International Business Context: Beyond an Instrumental Approach”, Target, vol. 9, no. 1, 1997, pp. 131-54.

THOMSON-WOHLGEMUTH Gaby and THOMson Ian, “Acquiring capabilities in translation: towards a model of translation businesses", Target, vol. 16, no. 2, 2004, pp. 253-88.

WENGER Etienne, Communities of Practice: Learning, Meaning, and Identity (Learning in Doing: Social, Cognitive and Computational Perspectives), Cambridge University Press, 1999, 309 p.

WOLF Michaela and FUKARI Alexandra (eds), Constructing a Sociology of Translation, Amsterdam and Philadelphia, John Benjamins Publishing Company, 2007, 226 p.

VAN LEEUWEN Theo, “A representação dos actores sociais”, in Emília Ribeiro Pedro (org.), Análise Crítica do Discurso, Lisbon, Editora Caminho, 1997, 304 p. 


\section{NOTES}

1. The site is available at <http://www.proz.com/faq/general\#gen_proz> [accessed 18 September 2008].

2. For more information: <http://www.proz.com/english-to-portuguese-translators> [accessed 18 September 2008].

3. F. Ferreira-Alves, "Linking Professional Practice with Translation Training in a BusinessOriented Setting: The Portuguese Association of Translation Companies Example", 2006, in Proceedings of the Bath Symposium (Editors: Valerie Pellatt and Elena Minelli), 2008, pp. 42-57. Available at <http://www.c-s-p.org/Flyers/Proceedings-of-the-Bath-Symposium1-84718-832X.htm> [accessed $1^{\text {st }}$ June 2011].

\section{ABSTRACTS}

This paper focuses on individual translators as a professional group in which tensions and clashes occur, and where different strategies are formed towards building a specific professional identity. Based on a professional attitude marked by hybrid discourses and a strong dichotomy between visibility and invisibility, this analysis aims to map the ways that lead to the construction of a professional identity profile among the Language Service Providers operating in the North of Portugal. Our basic assumption is that translation is both a powerful profitgenerating activity and an interdisciplinary social phenomenon.Based on the findings of a survey designed to determine the sociological profile of the associate members of the Portuguese Association of Translation Companies (APET), this papers proposes to briefly contextualise the translation industry in Portugal, provide new insights into market expectations and help to build a picture of the ideal translation service provider, according to prescriptive professional standards and to new business-oriented settings. Finally, we focus on individuals and their position regarding socio-professional variables by mapping how professional relations, task organisation and management-related issues are dealt with by different actors and by analysing their professional discourse and the impact of these variables/perceptions on the construction of a specific professional culture/identity. This should lead to better contextualisation of the nature of professionalisation, professional culture/perceptions and socialising routines as applied to translators.

Le présent article propose d'étudier les traducteurs en tant que groupe professionnel confronté à des tensions et à des affrontements, ainsi que les différentes stratégies mises en place pour la construction de leur identité professionnelle.

Ce contexte professionnel est marqué par des discours hybrides, mais aussi par une forte dichotomie entre visibilité et invisibilité, que nous proposons ici d'identifier à travers les parcours de professionnalisation des prestataires de services linguistiques qui opèrent dans la région nord du Portugal. Nous partons de la prémisse que la traduction est à la fois une puissante activité génératrice de profit et un phénomène social interdisciplinaire.

À partir des résultats obtenus au moyen d'une enquête réalisée afin de définir le profil sociologique des membres/associés de L'APET (Association portugaise des entreprises de 
traduction), nous donnerons ici une brève description de l'industrie de la traduction au Portugal et des nouvelles tendances du marché et tenterons de cerner ce que l'on entend par le profil idéal du traducteur en tant que prestataire de services, défini par la prescription de nouvelles normes professionnelles et de nouveaux paramètres à vocation commerciale. Nous nous centrerons enfin sur les individus et sur leur position en fonction des variables socio-professionnelles en jeu, pour comprendre comment ils traitent les relations professionnelles, l'organisation des tâches et les questions liées à la gestion, en analysant le discours professionnel et l'impact de ces variables/ perceptions/représentations sur l'identité professionnelle. En conclusion, cette étude devrait permettre de mieux contextualiser le statut de professionnalisation, et les représentations professionnelles ainsi que les routines sociales du traducteur.

INDEX

Mots-clés: prestataire de service en traduction, professionnalisation, sociologie de la traduction, traduction professionnelle

Keywords: professional translation, professionalisation, sociology of translation, translation service provider

\section{AUTHOR}

FERNANDO FERREIRA-ALVES

University of Minho, Portugal 